\title{
Psychosocial, Emotional problems and Development of Psychopathology among University Students
}

Atiqa Bano* and Nazia Iqbal

Department of Psychology, International Islamic University, Islamabad, Pakistan

\begin{abstract}
The present study was conducted to identify the psychosocial and emotional problems and development of psychopathology among university students. 120 university students participated in this study i.e., (60 male and 60 female). The "University student evaluation of psychosocial problem scale" (USEPP), The Hopkins Symptoms Checklist (HSCL), were used to collect authentic data from the students. The alpha reliability of measures were ranged from 0.80 to 0.85 on the said population. The data was analyzed statistically by using SPSS (version 20) through computing reliability coefficient, correlation coefficient, regression analysis, t-test and anovas. According to the results, the psychosocial and emotional problems are significantly correlated with each other. Psychosocial and emotional problems were found to have a predicting role in psychopathology among university students. Neither gender nor income or age significant differences found in the manifestation of psychopathology. Findings may be useful to further understanding of the psychosocial and emotional problems and their role in development of psychopathology and determine possible interventions or rehabilitation programs at university level or in educational institutions.
\end{abstract}

Keywords: Psychosocial; Emotional problems; Psychopathology; University students

\section{Introduction}

The university life of an individual is more demanding in different aspects as emotionally, intellectually, socially and morally than any other stage of life especially in any phase of education. Most of the students in this stage of life usually experience the work pressure and the new challenges Usually at this stage mostly students faces a great deal of work pressures and challenges that most of the time cause different forms of psychological, physical, social and emotional difficulties. And most of the time the students unable to cope with these difficulties and challenges as because of changing environment and its demands they become more vulnerable to develop mental health problems.

Mostly students face emotional problems along with psychosocial problems thus in this case Special education teachers can be a major influence in assisting regular education teachers to understand students with behavioral and emotional problems. Most of the time teachers may misunderstand the behavior of students. Thus these behavior patterns may lead students to develop mental health related issues. The small level of psychosocial and emotional problems may lead them to produce severe psychopathological conditions. Psychosocial problems are described as these are maladaptive, unhealthy or negative emotional, intrapersonal states of the behavior and as a result they lead an individual towards the development of negative, unhealthy and maladaptive behaviors and it is highly connected to the poor social functioning [1].

The psychosocial problems than any other psychiatric illness are reported to occur among university students during in examination and study time and it has a greater relationship with the students' performance in the most considerable event of their own and family [2]. Studies in emotion regulation have identified the relationship between the emotional problems, their psychological wellbeing and the mental health. Maladaptive feeling control and dysregulation of emotions are recognized as a reason and outcome of various psychological issues [3].

Studies of Salzer [4] also suggested that the students of college who are facing emotional distresses are usually did not involve in different events of university and they have very poor relationships, and these factors are mostly linked with poor performances. Research studies of Pledge et al. [5] identified that university students possess severe level of psychopathologies along with the issues of adjustment and other challenges, which includes depression, anxiety, substance abuse, suicidality, and history of psychiatric treatment or hospitalization.

Other studies show that if students' psychosocial, emotional problems and psychopathology is unchecked for a longer period of time then and it has worst impacts on the everyday functioning and it also affect their relationships and as a result it is possible that they face conflicts and instabilities in their future [6]. Psychopathology frequently exhibited as the anxiety and depression which is stated as "Stress" by the students of university and it usually lead to create issues in attention, scarcity of awareness and enthusiasm, absentees and other illnesses like sleep problems and nuisances.

Studies of Hunt and Eisenberg [7], explored that the severity and the number of psychological problems are increased day by day. Most of the time the psychosocial problems effect the students to daily functioning specially their studies, their participation in societal activities and their relations are also troubled. Most of the time the study related pressures in students may be responsible to develop psychopathological tendencies than any other populations [8].

Grayson [9] identified that university students face different concerns like disturbances in moods, relationship problems, and

*Corresponding author: Atiqa Bano, MS Scholar, Department of Psychology, International Islamic University, Islamabad, Pakistan, Tel: +92-51-9257988 Fax: +92-51-9257923; E-mail: aatiqa.khan2014@gmail.com

Received: October 23, 2018; Accepted: November 08, 2018; Published: November 15, 2018

Citation: Bano A, Iqbal N (2018) Psychosocial, Emotional problems and Development of Psychopathology among University Students. Clin Exp Psychol 4: 201. doi: 10.4172/2471-2701.1000201

Copyright: (C) 2018 Bano A, et al. This is an open-access article distributed unde the terms of the Creative Commons Attribution License, which permits unrestricted use, distribution, and reproduction in any medium, provided the original author and source are credited. 
destructive behavior which impair their self-concepts. Mental health problems among university students in Pakistan this issue is less researched and it got little attention. As Zaman [10] studied the medical students and his findings suggested that $39 \%$ of the students possess the symptoms of low mood, anxiety and $36 \%$, reported depression among $25 \%$, along with interpersonal and academic difficulties. Mostly students of the university possess mental health related concerns if they are not treated properly. As the studies of Shiels et al. [11] identified the incidence of mental health related issues among university students through the use of email surveys. It was suggested that (47\%) students had anxiety and about $10 \%$ scored clearly for depression.

The identification of psychosocial and emotional issues and it develop pathological conditions and it is a primary research, this study can be replicated and enhanced on a large sample of student's in order to generalize the findings. It is also suggested for the future researchers that the identification of mental health issues among students must be explored by in-depth study.

This study also provide base to make rehabilitation strategies which would be designed for the students especially in academic institution there must be an educational psychologist or counselor in order to deal with the students psychosocial and emotional problems. Regardless of the limitations, this study fills some gaps in the current literature and sheds light on a population that deserves unyielding attention because there are large number of students having problems but they lack awareness. It also provide mental health guideline for psychosocial interventions for students.

\section{Research Methodology}

\section{Objectives}

1. To identify the psychosocial problems of university students.

2. To investigate the emotional problems of university students.

3. Identify the factors for the development of psychopathology.

\section{Hypothesis}

H1: Psychosocial and emotional problems are positively correlated to the pathological conditions development.

$\mathrm{H} 2$ : Students of university experience psychosocial and emotional problems.

H3: Individuals with emotional and psychosocial problems are at greater risk to develop psychopathology.

\section{Operational definitions}

Psychosocial problems: Psychosocial problems defined as the maladaptive, negative or unhealthy intrapersonal, behavioral and emotional status which leads an individual to develop unhealthy relationship building, and malfunctioning in university [1].

Emotional problems: Emotional problems or disorders is defined as a condition exhibiting one or more specific emotional and/or behavioral difficulties over a long period of time and to a noticeable degree, which badly affects educational performance and interpersonal relationships. (IDEA, Federal Register, February 10, 1993, p. 7938).

Psychopathology: The term Psychopathology states "it is the study of mental health related issues specifically mental distress, mental illness or exhibition of actions and experience which may be suggestive for the mental illness (Daily sciences, Blog, 2017).

\section{Statement of the problem}

Students usually have some sort of psychosocial and emotional problems but these problems are less studied and later on these are responsible to develop severe psychopathological conditions thus it is important to study that particular area to control the long term consequences.

\section{Participants}

This preliminary research in Pakistan is exploratory and descriptive. Participants for this study are 100 university students. Participant selection is done by using convenient sampling technique. As it is the non-probability sampling technique which depends upon the availability of the population.

\section{Design}

The most appropriate research design for this study is quantitative research design which is used to assess psychosocial and emotional problems along with the development of psychopathology among University Students.

\section{Procedure}

Sample of 100 University Students participated in this research study and research protocol was used during the data collection. The research protocol includes introduction of research and the research consent in which the participants were asked to fill the questionnaire if they are willing and left it fill if they are not willing to do so

\section{Measures}

\section{Demographic sheet}

It includes basic information related to name (optional), gender, age, nationality, marital status, and department.

\section{The University Students Evaluation of Psychosocial Problems Scale (USEPP)}

The psychosocial problems of the students were identified through the "University Students Evaluation Of Psychosocial Problems Scale (USEPP). The USEPP is a 37 item instrument designed to screen university student's psychosocial problems.

\section{The Hopkins Symptoms Checklist (HSCL)}

Psychopathology was defined as having symptoms of depression and or anxiety as measured by the Hopkins Symptoms Checklist (HSCL). The HSCL is a widely used psychological distress screening instrument in epidemiological The HSCL has an item checklist dealing with both anxiety and depression. Each item is rated on a scale from 1 (not at all) to 4 (extremely). Participants will be asked to respond to the items according to their experience during the previous week.

\section{Analysis}

The data is analyzed while using SPSS 20 version, data analytic strategy is based on two phases involved performing; (i) descriptive analysis (cross tabulation, frequencies, and percentages) (ii) Independent sample $t$ test (iii) ANOVA analysis (iv) to find out the relationship between variables correlation analysis was used. 


\section{Results}

This study investigates the relationship between emotional, psychosocial problems and development of psychopathology among university students. The data analytic strategy involved performing; (i) descriptive analysis (frequencies, and percentages), (ii) Independent sample $t$ test to examine the mean difference in male and female university students. (iii) ANOVA analysis of male, female students (BS, M.Sc, MS, PhD) (IV) Pearson product moment correlation analysis was used to examine the relationship between psychosocial and emotional problems and development of psychopathology (Table 1).

\begin{tabular}{|c|c|c|}
\hline Demographics & Frequency & $\%$ ages \\
\hline \multicolumn{3}{|c|}{ Age } \\
\hline 19 & 7 & 5.8 \\
\hline 20 & 10 & 8.3 \\
\hline 21 & 3 & 2.5 \\
\hline 22 & 23 & 19.2 \\
\hline 23 & 29 & 24.2 \\
\hline 24 & 26 & 21.7 \\
\hline 25 & 8 & 6.7 \\
\hline 27 & 3 & 2.5 \\
\hline 30 & 4 & 3.3 \\
\hline 36 & 1 & .8 \\
\hline 44 & 1 & .8 \\
\hline \multicolumn{3}{|c|}{ Education } \\
\hline BS & 43 & 35.8 \\
\hline M.Sc & 51 & 42.5 \\
\hline MS & 23 & 19.2 \\
\hline $\mathrm{PhD}$ & 3 & 2.5 \\
\hline \multicolumn{3}{|l|}{ Cgpa } \\
\hline Below 3 & 22 & 18.3 \\
\hline 3.2 & 37 & 30.8 \\
\hline 3.4 & 36 & 30.0 \\
\hline 3.6 & 11 & 9.2 \\
\hline 3.8 & 7 & 5.8 \\
\hline 4 & 7 & 5.8 \\
\hline \multicolumn{3}{|c|}{ Family Income } \\
\hline Below 25,000 & 16 & 13.3 \\
\hline $26,000-45,000$ & 31 & 25.8 \\
\hline $46,000-65,000$ & 34 & 28.3 \\
\hline Above 66,000 & 39 & 32.5 \\
\hline
\end{tabular}

Table 1: Demographic characteristics of participants $(n=120)$.
This table describes demographic variables of the present study. The sample includes 120 students i.e., 60 female students (50\%) and 60 male students $(50 \%)$, among them $(21.7 \%)$ age range is $24,(24.2 \%)$ age range is $23,(19.2 \%)$ age range is $22,(8.3 \%)$ age range is $20,(.8 \%)$ age range is 36 and $44,(6.7 \%)$ age range is $25,(5.8 \%),(3.3 \%)$ age is range is 30 , and $(2.5 \%)$ individuals age range is 21 and 27 . In the category of education (35.8\%) students are in BS, (42.55\%) are in M.Sc, (19.2\%) are in MS level, while only (2.5\%) students are in $\mathrm{PhD}$. The Cgpa categories show that (18.3\%) students Cgpa is below 3, (30.8\%) Cgpa is 3.2, (30.0\%) students Cgpa is 3.4, (9.2\%) students Cgpa is 3.6, (5.8\%) students Cgpa is 3.8 and 4 .

Family income categories show (13.3\%) student's family income is below $25,000,(25.8 \%)$ family income is $26,000-45,000,(28.3 \%)$ student's family income is $46,000-65,000$ and (32.5\%) student's family income is above 66,000 (Table 2).

This table shows the descriptive statistics like mean, reliabilities, standard deviation and ranges of USEPP and Hopkins scale. The reliabilities of scores shows higher reliability coefficient. The values of skewness and kurtosis shows the normal distribution of data as values lie between +1 and -1 (Table 3 ).

The above table indicates no significant differences among the categories of male and female in relation to Hopkins scale and on USEPP subscales which shows that there is no differences exist in between male and female students (Table 4).

The above table indicates differences among the categories of joint and nuclear family systems in relation to the psychopathological tendencies and psychosocial and emotional problems. The table indicates the significant differences among the categories of joint and nuclear family systems in relation to AP (academic problems) (0.03, $\mathrm{p}<0.05)$ among family systems which indicates that students in nuclear family system ( $\mathrm{M}=8.88)$ experiencing more academic problems than students in joint family systems ( $M=7.38)$. Along with that the significant differences are also found in TE (traumatic experiences) $(0.04 \mathrm{p}<0.05)$ among family systems which indicates that students in nuclear family experience more traumatic experiences $(M=7.57)$ than students in joint family systems $(M=6.09)$ (Table 5).

Hopkins had positive relationship with EP, AS, TE and AP subscales of University Students Evaluation of Psychosocial Problems Scale (USEPP). Furthermore, the subscales of University Students Evaluation of Psychosocial Problems Scale (USEPP) are positively correlated with each other (Tables 6 and 7).

\begin{tabular}{|c|c|c|c|c|c|c|c|c|c|}
\hline \multicolumn{9}{|c}{ Parameters } & \multicolumn{2}{c|}{ No of } & \multicolumn{3}{c|}{ Ranges } \\
\hline Variables & $\mathbf{N}$ & $\mathbf{M}$ & S.D & $\boldsymbol{\alpha}$ & items & Actual & Potential & skewness & kurtosis \\
\hline Hopkins & 120 & 46.71 & 11.74 & .858 & 24 & $26-79$ & $24-96$ & .477 & -.403 \\
\hline USEPP & 120 & 32.69 & 12.88 & .804 & 37 & $9-65$ & $0-111$ & .221 & -.571 \\
\hline
\end{tabular}

Table 2: Psychometric properties of study variables $(n=120)$.

\begin{tabular}{|c|c|c|c|c|c|c|c|c|}
\hline \multirow{2}{*}{ Variables } & \multicolumn{2}{|c|}{ Male } & \multicolumn{2}{|c|}{ Female } & \multicolumn{2}{c|}{ CI } & LL & UL \\
\cline { 2 - 11 } & Mean & SD & Mean & SD & t (df) & p & -7.87 & 0.545 \\
\hline Hopkins & 44.88 & 10.94 & 48.55 & 12.31 & $1.72(118)$ & 0.087 & -4.16 & 0.295 \\
\hline EP (USEFP) & 11.6 & 6.33 & 13.53 & 5.98 & $1.71(118)$ & 0.089 & -1.64 & 2.07 \\
\hline AS (USEFP) & 5.88 & 5.03 & 5.66 & 5.25 & $0.231(118)$ & 0.818 & -1.76 & 1.06 \\
\hline TE (USEFP) & 6.35 & 4.08 & 6.7 & 3.72 & $0.491(118)$ & 0.625 & -1.27 & 1.23 \\
\hline AP (USEFP) & 7.81 & 3.59 & 7.83 & 3.34 & $0.26(118)$ & 0.97 & \\
\hline
\end{tabular}

Note: USEPP: University Student Evaluation of Psychosocial Problems, EP: Emotional Problems AS: Antisocial Behavior TE: Traumatic Experiences AP: Academic Problems, Cl: Confidence Interval, LL: Lower Limit, UL: Upper Limit.

Table 3: Mean standard deviation and independent sample $t$ test of both female and male students $(n=120)$. 
Citation: Bano A, Iqbal N (2018) Psychosocial, Emotional problems and Development of Psychopathology among University Students. Clin Exp Psychol 4: 201. doi: 10.4172/2471-2701.1000201

Page 4 of 6

\begin{tabular}{|c|c|c|c|c|c|c|c|c|}
\hline \multirow{2}{*}{ Variables } & \multicolumn{2}{|c|}{ Joint } & \multicolumn{2}{|c|}{ Nuclear } & \multicolumn{4}{|c|}{$\mathrm{Cl}$} \\
\hline & Mean & S.D & Mean & S.D & $t(d f)$ & p & LL & UL \\
\hline Hopkins & 47.03 & 10.79 & 45.94 & 13.93 & $.46(118)$ & 0.69 & -3.59 & 5.77 \\
\hline EP (USEPP) & 12.36 & 6.01 & 13.05 & 6.74 & $-0.55(118)$ & 0.58 & -3.17 & 1.78 \\
\hline AS (USEPP) & 5.21 & 4.79 & 7.14 & 5.69 & $-1.89(118)$ & 0.06 & -3.94 & 0.085 \\
\hline TE (USEPP) & 6.09 & 3.41 & 7.57 & 4.77 & $-1.90(118)$ & 0.04 & -3 & 0.005 \\
\hline AP (USEPP) & 7.38 & 3.41 & 8.88 & 3.35 & $-2.19(118)$ & 0.03 & -2.85 & -0.144 \\
\hline
\end{tabular}

Note: USEPP: University Student Evaluation of Psychosocial Problems, EP: Emotional Problems AS: Antisocial Behavior, TE: Traumatic Experiences AP: Academic Problems, Cl: Confidence Interval, LL: Lower Limit, UL: Upper Limit.

Table 4: Mean, standard deviation and independent sample t-test of joint and nuclear family systems $(n=120)$.

\begin{tabular}{|c|c|c|c|c|c|}
\hline Variables & Hopkins & EP of USEPP & AS of USEPP & TE of USEPP & AP of USEPP \\
\hline HP & 1 & $0.627^{* *}$ & $0.196^{*}$ & $0.425^{* *}$ & $0.235^{* *}$ \\
\hline EP & -- & 1 & 0.106 & $0.344^{* *}$ & $0.311^{* *}$ \\
\hline AS & -- & -- & \multirow{2}{*}{1} & $0.383^{* *}$ & $0.208^{*}$ \\
\hline TE & -- & -- & & \multirow{3}{*}{1} & $0.538^{* *}$ \\
\hline \multirow[t]{2}{*}{ AP } & \multirow[t]{2}{*}{--} & \multirow[t]{2}{*}{-- } & \multirow[t]{2}{*}{-- } & & 1 \\
\hline & & & & & 1 \\
\hline
\end{tabular}

Note: "*Correlation is significant at the 0.01 level (2-tailed).

*. Correlation is significant at the 0.05 level (2-tailed). Intercorrelations of university students $(n=120)$ are presented in the diagonal format. For all scales higher scores are more indicative of more extreme responding in the direction of the construct assessed. HP= Hopkins; EP= Emotional problems subscale of University Students Evaluation of Psychosocial Problems Scale (USEPP); AS = Anti-Social subscale of University Students Evaluation of Psychosocial Problems Scale (USEPP); TE = Traumatic Events subscale of University Students Evaluation of Psychosocial Problems Scale (USEPP); AP = Academic Problems subscale of University Students Evaluation of Psychosocial Problems Scale (USEPP); ${ }^{*} p<0.05,{ }^{* *} p<0.01$

Table 5: Correlational analysis of relationship among variables of measures.

\begin{tabular}{|c|c|c|c|}
\hline \multicolumn{4}{|c|}{$\begin{array}{l}\text { Model } \\
\text { Hopkins (measure of psychopathology) }\end{array}$} \\
\hline Variables & $\beta$ & UL & LL \\
\hline Constant & & [34.45-24.87] & [0.38-65] \\
\hline USEPP & 0.57 & -- & - \\
\hline $\mathrm{R}^{2}$ & 0.32 & -- & \\
\hline $\mathrm{F}$ & 57.42 & -- & -- \\
\hline$\Delta \mathrm{R}^{2}$ & 0.32 & -- & -- \\
\hline
\end{tabular}

Note: Simple linear regression is calculated to examine the effect of psychosocial and emotional problems measured by USEPP on the development of psychopathology. USEPP is found to be a significant predictor of the psychopathology among university students. $(\beta=.32, p<.05)$ by adding $32 \%$ variance in development of psychopathology.

Table 6: Effect of USEPP on development of psychopathology among University students $(n=120)$.

\begin{tabular}{|c|c|c|c|c|}
\hline Variables & Sum of Squares & df & Mean Square & F \\
\hline Between Groups & 1178.379 & 2 & 392.793 & 2.99 \\
\hline Within Groups & 15237.99 & 119 & 131.362 & - \\
\hline Total & 16416.37 & 119 & -- & - \\
\hline
\end{tabular}

Note: The effect of Hopkins was significant overall $(F 3,116=2.990, p=0.034)$. When Bonferroni adjustment was made for the number of comparisons, the significant differences was between the means of education groups. The mean of $B S$ students $(M=49.56, S D=10.43)$ was significantly greater than form $M$.Sc students $(M=45.18$, $S D=12.24) p<0.05$, furthermore, the mean scores of $M S$ student $(M=46.83, S D=0.12 .01)$ was significantly greater than $P h D$ students $(M=31.33, S D=1.54)$ and slightly greater from M.Sc students.

Table 7: ANOVA analysis of education groups on Hopkins $(n=120)$.

\section{Analysis and Discussion}

The purpose of the study was to assess the relationship between the psychosocial and emotional problems and development of psychopathology among students. Or this study determine either the students who were exposed to psychosocial and emotional problems can also prone to develop the tendencies of psychopathology. The psychopathology was measured by Hopkins scale, while the psychosocial and emotional problems was measured by USEPP (university student evaluation of psychosocial problems). The present study found out the relationship between psychosocial and emotional problems in the development of psychopathology.

According to hypothesis (I) psychosocial and emotional problems are positively correlated to the development of psychopathology among students. The results of current study indicated that psychosocial and 
Citation: Bano A, Iqbal N (2018) Psychosocial, Emotional problems and Development of Psychopathology among University Students. Clin Exp Psychol 4: 201. doi: 10.4172/2471-2701.1000201

Page 5 of 6

emotional problems are positively correlated with each other as well as the subscales of USEPP also had positive relationship with each other. It indicates that the students who are experiencing the psychosocial and emotional problems can develop the symptoms of psychopathology. These findings are consistent with the studies of Nsereko, et al. [12] as they explore that that students who are exposed to psychosocial problems also developed psychopathology exhibiting as depression and anxiety.

The study hypothesize that individuals with emotional and psychosocial problems are at greater risk to develop psychopathology. Findings of Omokhodion and Gureje [13] also support the findings of current study as university students who were exposed to significant life stressors developed psychopathological tendencies like depression and anxiety.

This study also hypothesized of this study is that university student's experience psychosocial and emotional problems. This study also identified that the university students experience a significant number of psychosocial problems. As the subscales of USEPP results explores that the university students experience tendencies of emotional problems, anti-social problems, recall traumatic events and experience academic problems. And all these are risk factors to develop psychopathological tendencies.

These results are consistent with another studies as researches showed that student's stressors such as financial problems, academic pressures and problems in social life have an adverse effect on the mental health of students [14].

The current research findings also reveal that university students experience the psychosocial and emotional problems and consequently these may lead them towards the development of psychopathology these results indicates that majority of students experience mental health related problems.

These findings are consistent with different research studies as mental health problems are highly widespread among students. In the 2008 National College Health Assessment supported by the American College Health Association (ACHA-NCHA), more than one in three undergraduates stated "mood so depressed it was difficult to function" at least once in the prior year, and approximately one in 10 stated "really considering trying suicide" in the past year.

Researchers also identified that students admitted in mental health services center of university indicates high levels of distress as compared with the general population. And increased distress was associated with increased disability among students [15].

\section{Conclusion}

On the Basis of the collected data, analysis and findings, the following conclusions were made as students experiencing psychosocial and emotional problems are more prone to develop the tendencies of psychopathology as these two constructs are positively correlated with each other. Results also depict that majority of students possess psychosocial and emotional problems and along with that they also possess pathological tendencies [16-24].

\section{Limitations}

Several limitations apply to this research as the results do not generalize to all students because the sample size is very small and comprised of a single segment of population that is only university students. It is possible that some participants may not understand the questions in the manner in which they are intended. The presence of confounding variables (such as environmental errors, participant errors etc.) influence the results.

\section{Recommendations}

The following recommendations are made from the findings of this research:

1. This study can be replicated and enhanced on a large sample of student's in order to generalize the findings.

2. There is greater need of effective mental health screening services at universities. As mental health related issues are present among university students. In this way the administration of university must have to set policies to deal with these issues.

3. It also provides mental health guideline for psychosocial interventions for students.

\section{References}

1. Laelia G, Apicella L, Brakarsh J, Dube L, Jemison K, et al. (2006) Orphans and vulnerable youth in Bulawayo, Zimbabwe: An exploratory study of psychosocial well-being and psychosocial support.

2. Lucas CJ (1976) Aspects of student health psychological problems of students Br Med J 2: 1431-1433.

3. Arndt JE, Fujiwara E (2014) Interactions between emotion regulation and mental health. Austin J Psychiatry Behav Sci 1: 1021.

4. Salzer MS (2012) A comparative study of campus experiences of college students with mental illnesses versus a general college sample. J Am Coll Health 60: 1-7.

5. Pledge D, Lapan R, Heppner P, Roehlke H (1998) Stability and severity of presenting problems at a university counselling center: A 6-year analysis. Prof Psychol Res Pr 24: 386-389.

6. Blignault I, Bunde-Birouste A, Ritchie J, Silove D, Zwi BA (2009) Community perceptions of mental health needs: A qualitative study in the Solomon Islands. International Journal of Mental Health Systems.

7. Hunt J, Eisenberg D (2010) Mental health problems and help-seeking behavior among college students. J Adolesc Health 46: 3-10.

8. Kitzrow MA (2003) The mental health needs of today's college students: Challenges and recommendations.

9. Grayson PA (1989) The college psychotherapy client: An overview. In Grayson PA, Cauley K (Eds.), College Psychotherapy (pp 8-28). The Guilford Press, New York.

10. Zaman RM (1996) Psychological problems of medical students in Pakistan Data from the Aga Khan University, Karachi. Teaching and Learning in Medicine 8: 19-27.

11. Shiels C, Gabbay M, Exley D (2008) Psychological distress in students registered at a university-based general practice. Primary Care and Community Psychiatry 13: 9-18.

12. Nsereko N, David NN, Seggane M, Janet N, Denis S (2014) Psychosocia problems and development of psychopathology among Ugandan university students. International Journal of Research Studies in Psychology 3: 3-16.

13. Omokhodion F, Gureje O (2003) Psychosocial problems of clinical students in the University of Ibadan. Afr J Med Med Sci 32: 55-68.

14. Omigbodun OO, Odukogbe AT, Omigbodun AO, Yusuf OB, Bella TT, et al. (2006) Stressors and psychological symptoms in students of medicine and allied health professions in Nigeria. Soc Psychiatry Psychiatr Epidemiol 41: 415-421.

15. Stallman HM (2008) Prevalence of psychological distress in university studentsimplications for service delivery. Aust Fam Physician 37: 673-677.

16. American College Health Association (2008) American College Health Association-National Health Assessment: Reference Group Data Report (2008) American College Health Association: Baltimore, UK. 
Citation: Bano A, Iqbal N (2018) Psychosocial, Emotional problems and Development of Psychopathology among University Students. Clin Exp Psychol 4: 201. doi: 10.4172/2471-2701.1000201

Page 6 of 6

17. Buckley JA (2009) Implementing evidence-based interventions in elementary schools for students with and at risk for severe behavior disorders. J Emot Behav Disord 17: 195-196.

18. Drum DJ, Brownson C, Denmark AB, Smith ME (2009) New data on the nature of suicidal crises in college students: Shifting the paradigm. Prof Psychol Res Pr 40: 213-222.

19. Ovuga E, Boardman J, Wasserman D (2006) Undergraduate student mental health at Makerere University, Uganda. World Psychiatry 5: 51-52.

20. Eisenberg D, Gollust SE, Golberstein E, Hefner JL (2007) Prevalence and correlates of depression, anxiety, and suicidality among university students. Am J Orthopsychiatry 77: 534-542.
21. Harper R, Peterson M (2005) Mental health issues and college students. NACADA Clearinghouse of Academic Advising Resources.

22. Mahmood Z, Saleem S (2011) Assessing psychological problems in university students in Pakistan: A psychometric study. FWU Journal of Social Sciences 5: 134-148.

23. Rimmer JD, Halikas JA, Shuckit MA (1982) Prevalence and incidence of psychiatric illness in college students: A four year prospective study. J Am Coll Health 30: 207-211.

24. Stallman HM, Shochet I (2009) Prevalence of mental health problems in Australian university health services. Australian Psychologists 44: 122-127. 